\title{
Raman Microspectroscopy of some High Explosives heated to High Temperatures
}

\author{
Edgar S. Etz, Sonya V. Roberson, and Greg Gillen \\ Chemical Science and Technology Laboratory, National Institute of Standards and Technology, \\ Gaithersburg, Maryland 20899-8371
}

In collaboration with the Transportation Security Agency's (TSA) Trace Explosives Detection Group, the Chemical Science and Technology Laboratory of NIST has been working to establish a chemical metrology program to help support the current operational deployment and effective utilization of trace explosives detection devices throughout the United States. The majority of detection systems for high explosives (HEs) are based on either airborne or surface swipe collection of micrometersized explosives particles, followed by thermal vaporization of the particles into an ion mobility spectrometer (IMS) for sample identification [1]. The effective collection and thermal desorption of the HE particles, in this scheme, is critical to the reproducible and successful detection of any sparse collection of explosives material.

We have recently initiated a research program to study this critical front-end process in detail. It involves experiments to evaluate both the sample-swipe and portal-based explosives detection systems, with a focus on particle transport and HE thermalization-vaporization for the IMS detection system. In these processes, it is of interest also to understand the temperature behavior and thermochemistry of the analyte HEs over the temperature range leading to the melting temperature, and beyond to the vapor phase. This is of importance as the fragmentation of HEs by atmospheric pressure chemical ionization reactions determines the ion mobility spectra produced by IMS. Toward this goal, we are using Raman microspectroscopy to study the microparticle spectra of the most relevant HEs heated up to their melting point on a microscope hot-stage. The resultant spectra are examined for (i) shifts in the peak frequency of Raman bands, (ii) temperature-induced changes in the halfwidth and asymmetry of bands, (iii) changes in the relative intensity of bands, and (iv) possible phase transformations with temperature. The spectra reported here (with $4 \mathrm{~cm}^{-1}$ resolution) are excited at $532 \mathrm{~nm}$ and are acquired with a commercial micro-Raman system employing a cooled CCD detector. Discussed are the preliminary results obtained for the crystalline explosives PETN (pentaerythritol tetranitrate, m.p. $=141.3{ }^{\circ} \mathrm{C}$ ) and $\mathrm{RDX}$ (cyclo-1,3,5-trimethylene-2,4,6-trinitramine, m.p. $=204^{\circ} \mathrm{C}$ ), studied over the temperature range $10-160{ }^{\circ} \mathrm{C}$, in steps of $10{ }^{\circ} \mathrm{C}$, both in ascending and descending order. The ambient temperature Raman spectra of these, and other HEs, have been reported, but no detailed band assignments are available for these complex molecular solids [2].

From the temperature series on PETN, the spectra recorded at 60,140 , and $150{ }^{\circ} \mathrm{C}$ are shown in Fig. 1. For RDX, the microparticle spectra are shown in Fig. 2 for 20,80 , and $150^{\circ} \mathrm{C}$. What these results show is that there are noticeable changes in these spectra as the sample is ramped up to the higher temperatures (e.g., $140{ }^{\circ} \mathrm{C}$, just below the m.p. of PETN). The temperature-induced changes in the spectra take on various forms, as is shown in Fig. 3 for PETN, at 60 and $140{ }^{\circ} \mathrm{C}$, over the expanded Raman range $400-1700 \mathrm{~cm}^{-1}$. These changes consist of peak frequency shifts, for some of the bands, of the order of up to $4-5 \mathrm{~cm}^{-1}$, band broadening with lowering of symmetry, and fairly pronounced relative intensity changes.

For PETN, there is no polarization dependence of the spectrum, whereas for RDX many of the major bands are polarized [2]. Transitioning the melting temperature of PETN brings on sample 
degradation as evidenced by the loss in spectral features as a high luminescent background develops. Further studies of these systems are aimed at elucidating the detailed structural changes as the HEs undergo temperature-induced decomposition.

[1] S.F. Hallowell, Talanta 54 (2001) 447, and R.G. Ewing et al. Talanta 54 (2001) 515.

[2] C. Cheng et al., J. Forensic Sci. 40 (1995)31, and N.F. Fell et al. J. Raman Spectrosc. 27 (1996) 97.
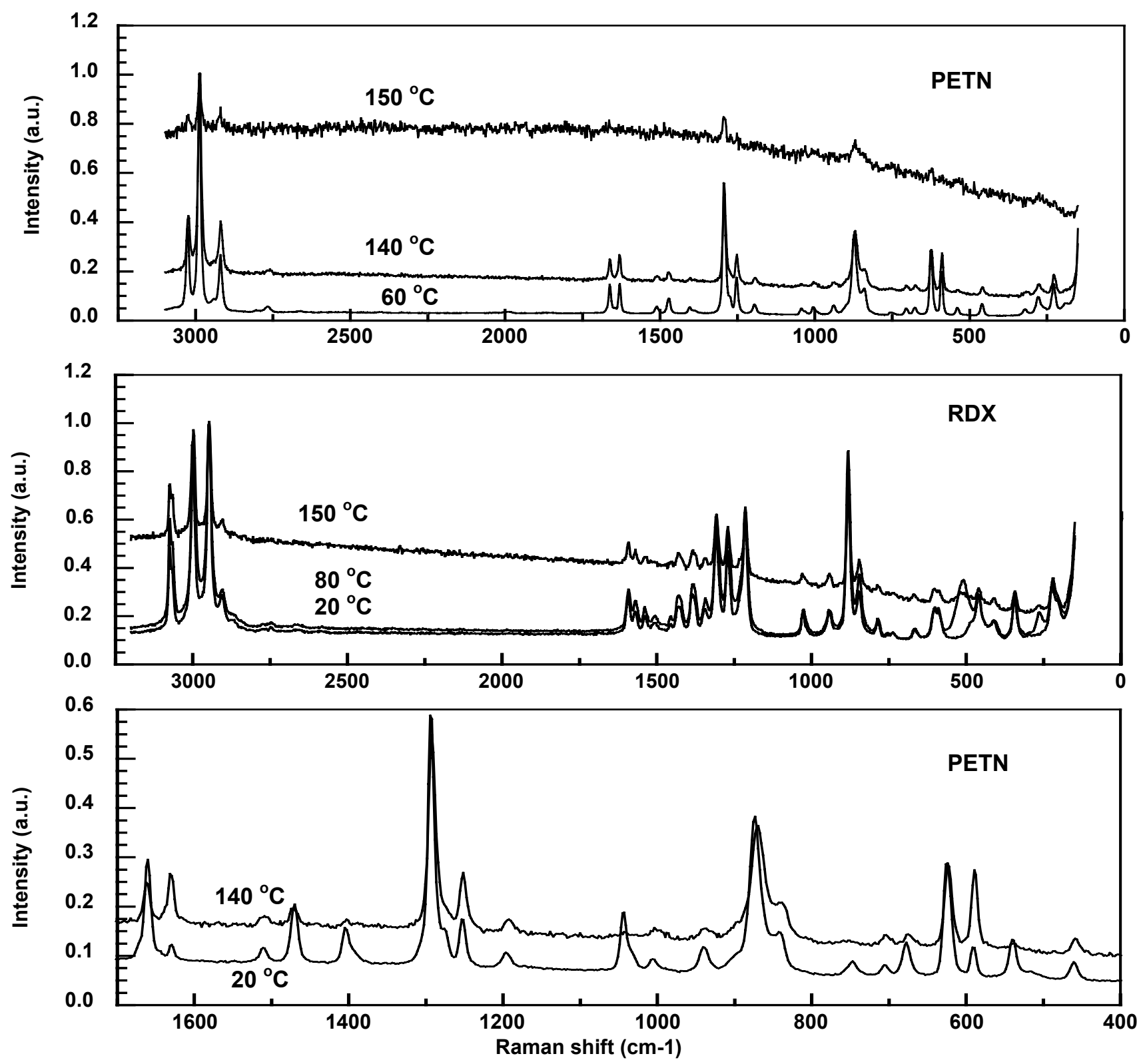

FIG. 1: Superposition of the micro-Raman spectra, excited at $532 \mathrm{~nm}$, of a microparticle (crystal) of PETN, at 60, 140 , and $150^{\circ} \mathrm{C}$. At $150^{\circ} \mathrm{C}$, the solid has gone past its melting point, with onset of degradation-decomposition.

FIG. 2: Superposition of the micro-Raman spectra, excited at $532 \mathrm{~nm}$, of a microparticle (crystal) of RDX, at 20, 80 , and $150^{\circ} \mathrm{C}$. Even at the highest temperature, no sample degradation is noted.

FIG. 3: Two of the micro-Raman spectra of PETN, here at 20 and $140{ }^{\circ} \mathrm{C}$, overlaid across the expanded spectral range $400-1700 \mathrm{~cm}^{-1}$. to show band shifts, band broadening. and relative band intensity changes with temperature. 